\title{
48. LA REVISIÓN DE LOS TRATADOS EUROPEOS
}

\author{
JOSÉ LUÍS DA CRUZ VILAÇA
}

Presidente del Tribunal de Primera Instancia de las Comunidades Europeas

y

NUNO PIÇARRA

Letrado del Tribunal de Primera Instancia de las Comunidades Europeas 


\section{SUMARIO}

I. Introducción.-II. Los Estados Miembros ya no son dueños de LOS TRATADOS. 


\title{
48. REVISIÓN DE LOS TRATADOS EUROPEOS
}

\author{
POR \\ JOSÉ LUÍS DA CRUZ VILAÇA \\ Presidente del Tribunal de Primera Instancia \\ de las Comunidades Europeas \\ y \\ NUNO PIÇARRA \\ Letrado del Tribunal de Primera Instancia \\ de las Comunidades Europeas
}

\section{INTRODUCCIÓN}

En una lección impartida en la Facultad de Derecho de la Universidad Libre de Bruselas en febrero de 1964, Michel WAELBROECK, al examinar la cuestión de si puede hablarse de un Derecho constitucional europeo, consideraba que el hecho de que las Comunidades Europeas hubiesen sido creadas por Tratados internacionales no era suficiente para negar la naturaleza constitucional del Derecho que rige su organización, su funcionamiento y -añadiríamos hoy- sus relaciones con los ciudadanos comunitarios. Y el autor resaltaba la «impresionante semejanza con las estructuras constitucionales de los Estados federales" que ponía de relieve la existencia de una asamblea parlamentaria integrada por representantes de los pueblos de los Estados miembros, de un Consejo que, debido a su composición y a las amplias competencias legislativas de que dispone, no deja de presentar analogías con el Senado de un Estado federal, y de un órgano ejecutivo independiente, como es la Comisión. 
La conclusión a la que llegaba era, no obstante, la de que uen las circunstancias actuales, todavia no es posible hablar de un Derecho constitucional europeo, a no ser que se dé a la expresión un significado amplio y se haga uso de la analogía», toda vez que "el Derecho comunitario aún no ha adquirido, en relación con el de los Estados miembros, aquella autonomía sin la cual no puede merecer, en rigor, el calificativo de constitucional".

No se me habría ocurrido citar un texto escrito hace casi treinta años como introducción al tema sobre el que me ha tocado hablar, si no fuese porque la conclusión que reproduzco se fundamenta, ni más ni menos, en la diferencia entre el modo de revisión de los Tratados constitutivos de las Comunidades Europeas y el modo de revisión de cualquier Constitución federal, y tiene como punto de partida la premisa de que "la distinción fundamental entre Constitución y Tratado internacional estriba en el diverso procedimiento que debe seguirse para poder modificar $o$ derogar legalmente cada uno de esos dos instrumentos" '. Esta es la razón de que el texto citado me parezca tan idóneo para «servir de puente»-entre el tema general de estas jornadas y el tema específico que me incumbe.

Para el autor - $y$ este punto es fundamental--, la mencionada diferencia obedecía menos al contenido de las cláusulas de revisión insertas en cada uno de los Tratados constitutivos de las Comunidades. Europeas (art. 96 del Tratado CECA, art. 236 del Tratado CEE y art. 204 del Tratado CEEA) que a la práctica de revisión desarrollada en el ínterin, caracterizada por la inobservancia de las formalidades especiales previstas al efecto en las referidas cláusulas. En otras palabras: para el autor, tales cláusulas, al representar un plus con respecto a los Tratados internacionales ordinarios, tenían ya alcance constitucional, por más que éste fuese limitado; la práctica seguida hasta la fecha, sin embargo, se guiaba casi exclusivamente por los principios generales del Derecho internacional común en materia de revisión de Tratados.

Conviene dejar bien claro desde ahora un punto extremadamente importante. Las cláusulas de revisión de los tres Tratados, en cuya interpretación basó Michel WAELBROECK su tesis, están todavía vigentes, y así se mantendrán por lo menos hasta el 1 de enero de 1993, fecha previsible para la entrada en vigor del Tratado de la Unión Europea, que fue firmado en Maastricht el 7 de febrero de 1992. Esto quiere decir que, si se pudiera comprobar que la práctica de revisión de los Tratados constitutivos de las Comunidades Europeas, seguida desde 1964 hasta hoy, se ha caracteriza-

1 Véase Michel WAELBROECK: «Peut-on parler d'un droit constitutionnel européen?", en Travaux et Conférences de la Faculté de Droit de I'ULB, vol. 2, págs. 75 y ss. especialmente págs. 78-79. 
do por la estricta observancia de lo dispuesto en las respectivas cláusulas de revisión, habrá que reconsiderar, sin más, la tesis de Michel Waelbroeck.

Empezaré analizando, desde un punto de vista técnico-juridico, por un lado, las cláusulas de revisión del Tratado CECA, firmado en París el 18 de abril de 1951 y que entró en vigor el 23 de julio de 1952, y, por otro, las del Tratado CEE y las del Tratado CEEA, firmados en Roma el 25 de marzo de 1957 y que entraron en vigor el 14 de enero de 1958, procurando poner de relieve lo que las distingue de las normas de revisión de la Constitución de un Estado federal, pero también lo que las aproxima a ellas. Voy a referirme enseguida a la aplicación práctica de las diversas cláusulas de revisión de los Tratados y, en particular, a las principales revisiones de que han sido objeto, citando la jurisprudencia del Tribunal de Justicia de las Comunidades Europeas más importante sobre el tema.

El Tratado de la Unión Europea merecerá una referencia especial, como no podía ser menos. Voy a analizar las cláusulas de revisión contenidas en el mismo, sin olvidar encuadrarlo en el debate que lo precedió sobre el destino de los Tratados comunitarios en la perspectiva de la Unión Europea, ni tampoco de relacionarlo, a este respecto, con el proyecto de Tratado de Unión Europea presentado por el Parlamento Europeo el 14 de febrero de 1984.

Por último, contrastaré la tesis que me sirvió de punto de partida - la diferencia específica entre Tratado comunitario y Constitución radica en el respectivo modo de revisión-con los datos recabados y con las conclusiones que pueden extraerse de los mismos. A la luz de ellos y de la controversia doctrinal sobre el sentido, el alcance práctico y la garantía de las cláusulas de revisión contenidas en los Tratados Europeos, intentaré dar una respuesta a la cuestión de si el Derecho comunitario primario tiene naturaleza constitucional o no la tiene. En otras palabras, procuraré responder a la discutida cuestión de determinar qué valor jurídico tienen las revisiones de los Tratados efectuadas al margen del procedimiento que en ellos se establece o, lo que es lo mismo, la de determinar si los Estados miembros siguen siendo dueños de esos Tratados.

\section{LOS ESTADOS MIEMBROS YA NO SON DUEÑOS DE LOS TRATADOS}

En virtud de un conocido principio general del Derecho internacional -con expresión formal en la Convención de Viena sobre el Derecho de 
los Tratados, firmada el 23 de mayo de 1968 (artículos 39, 54 y 57)— los Estados parte en un Tratado, sea cual fuere, son "dueños del Tratado", pudiendo en todo momento modificarlo o revocarlo libremente, formalmente o no, en principio con arreglo a la regla de la unanimidad. Incluso cuando un Tratado contenga cláusulas que limiten su revisión o prevean un determinado período de vigencia, las partes podrán hacer caso omiso de ellas por común acuerdo.

Siendo así las cosas, ¿pueden los Estados miembros modificar los Tratados constitutivos de las Comunidades Europeas sin observar las cláusulas de revisión en ellos contenidas, 0 , incluso, revocarlos pura y simplemente? A la luz de los principios del Derecho internacional público que acabo de enunciar, difícilmente se podrá mantener que los Tratados constitutivos de las Comunidades Europeas, así como los Tratados que los modifiquen y complementen, no puedan ser modificados e incluso revocados en todo momento, mediante el mero acuerdo unánime de los Estados miembros ${ }^{2}$.

La cuestión, sin embargo, no ha quedado resuelta, pues de lo que se trata es de determinar si a los Tratados comunitarios les siguen resultando aplicables con carácter ilimitado las normas imperativas del Derecho internacional o si, por el contrario, aquellos Tratados forman parte de un ordenamiento jurídico autónomo, tanto en relación con el ordenamiento jurídico internacional como en relación con el de los Estados miembros. Procuraré responder enseguida a esta última cuestión, no sin antes destacar que las cláusulas de revisión previstas en los Tratados comunitarios, que consagran el principio del acuerdo unánime el Derecho internacional ${ }^{3}$. La participación de las Instituciones comunitarias en el procedimiento de revisión, por su parte, también encuentra paralelo en varios Tratados constitutivos de organizaciones internacionales. La divergencia con el Derecho internacional tan sólo se verifica, por lo tanto, en lo relativo al principio de la libertad de forma: mientras que en Derecho internacional un Tra-

2 En este sentido, véase por todos Marguerite DeliEgE-Sequaris: «Revision des traités européens en dehors des procédures prévues", en Cahiers de Droit Européen, 1980, pág. 550, así como los autores allí citados. En las páginas 543-546, la autora expone y refuta los argumentos de aquella corriente doctrinal que, basándose en los principios generales del Derecho internacional, especialmente en materia de revisión y revocación de los Tratados, tal como están consagrados en el Convenio de Viena (art. 26, art. 54 en relación con el art. 39, art. 40 y art. 5), mantiene que no pueden revisarse legalmente los Tratados comunitarios al margen de los procedimientos de revisión previstos en los mismos, ni siquiera con arreglo al ordenamiento jurídico internacional.

3 Cfr. LouIs: «Quelques considérations sur la révision des traités instituant les Communautés", en Cahiers de Droit Européen, 1980, pág. 554. 
tado, incluso ratificado por cada una de las partes con arreglo a sus respectivas normas constitucionales, puede ser modificado mediante un acuerdo concluido en forma simplificada entre los Gobiernos de las partes contratantes, las cláusulas de revisión comunitarias excluyen la revisión del Derecho comunitario primario mediante tales acuerdos.

Que los tratados comunitarios no son Tratados "como los demás" es hoy un punto incontrovertido y suficientemente acreditado por una experiencia de más de treinta años. En efecto, los Tratados comunitarios crearon un nuevo sujeto de Derecho, dotado de sus propios órganos y de sus propios derechos de soberanía (resultado, es verdad, del consentimiento de los Estados miembros a limitar su propia soberanía), y que actúa de manera autónoma a través del ejercicio de las funciones legislativa, ejecutiva y judicial proprio sensu. En esta creación sin parangón en el Derecho internacional, dotada de condiciones para evolucionar por sí misma hacia formas de integración supranacional cada vez más perfectas, no puede dejar de distinguirse - y más que nunca en vísperas de la previsible entrada en vigor del Tratado de la Unión Europea- entre su origen, basado en el Derecho internacional, y su funcionamiento, que es equiparable al de un ordenamiento jurídico estatal. El "acervo comunitario" $y$, en particular, la jurisprudencia del Tribunal de Justicia, en cuanto pilar de la referida integración supranacional, a partir de la "constitucionalización" de los Tratados 4 , hablan por sí mismos a la hora de determinar la diferencia específica entre el ordenamiento jurídico comunitario $y$ el ordenamiento jurídico internacional 5 .

Es indiscutible que los Tratados europeos no pueden ser analizados como la Constitución de un Estado federal. Pero no resulta menos evidente que este argumento hoy ya no basta para, basándose en esa misma razón, mantener que continúan rigiéndose plenamente por el ordenamiento jurídico internacional y que, por consiguiente, el carácter vinculante o no

4 La "constitucionalización" de los Tratados constitutivos de las Comunidades Europeas conlleva un proceso circular o mejor "en espiral» en el que esos Tratados son interpretados mediante técnicas de derecho constitucional y no de derecho internacional público, asumiendo, como causa y efecto simultáneos de dicho proceso, las características de "ley superior" propias de una Constitución. Para un análisis de ese proceso véase E. STEIN: "Lawyers, judges, and the making of a transnational constitution", en The American Journal of International Law, 1981, págs. 1 y ss.

5 En lo relativo a la autonomía, aplicabilidad directa y primacía del ordenamiento jurídico comunitario, recuérdese las conocidas sentencias Van Gend and Loos, de 5 de febrero de 1963, asunto 26/62, Rec. 1963, pág. 1 y ss.; Costa/ENEL, de 15 de julio de 1964, asunto 6/64, Rec. 1964, pág. 1141 y ss.; Simmenthal, de 9 de marzo de 1978, asunto 106/77, Rec. 1978, pág. 629 y ss. 
de sus cláusulas de revisión tiene que decidirse a la luz de las normas del Derecho internacional público ${ }^{6}$.

Por otro lado, difícilmente puede negarse que una decisión unánime de los Estados miembros será, de facto, capaz de poner fin a las Comunidades Europeas y a su ordenamiento jurídico o para introducir en el mismo modificaciones radicales. Pero en ningún caso podrá esta situación de facto conferir por sí sola validez jurídica a tal decisión. Como afirma Rudolf BERNHARDT, se trataría de un "acto ciertamente revolucionario que no estaría basado en el Derecho vigente" ' . Tampoco se ve a priori en qué circunstancias tal acto revolucionario ilegal podría ser considerado legítimo. El hecho de que las Comunidades no estén en condiciones de impedir que los Estados miembros adopten una decisión con ese contenido no basta para fundamentarla jurídicamente, a no ser que se parta de la base de una concepción imperativa del Derecho (que supedita el carácter jurídico a la garantía de sanción jurisdiccional), concepción que es especialmente poco adecuada tanto en el contexto que se analiza como para el Derecho público en general.

En virtud de las consideraciones precedentes puede llegarse a la conclusión de que los criterios de validez que deben utilizarse en primer lugar para valorar una revisión de los Tratados comunitarios, realizada por acuerdo unánime de los Estados miembros pero con inobservancia de las cláusulas de revisión contenidas en aquéllos, no son los del Derecho internacional público sino los del Derecho comunitario. A la luz de este Derecho, tal revisión ha de considerarse inválida, máxime cuando las mencionadas cláusulas no son facultativas (Sollvorschrifte) para los Estados miembros sino obligatorias ${ }^{8}$.

Queda por determinar cuáles son las consecuencias prácticas de dicha invalidez, cosa que en amplia medida depende de la cuestión de si el Derecho comunitario dispone de medios para garantizar el cumplimiento de las mencionadas obligaciones y en qué condiciones dispone de ellos. En otras palabras, se trata, entre otras cosas, de determinar si el sistema comunitario de control de la legalidad de los actos jurídicos se extiende a los actos de revisión de los Tratados y en qué medida lo hace.

Que los Tratados comunitarios no pueden revisarse válidamente mediante acuerdos unánimes adoptados en forma simplificada por los Es-

6 En sentido contrario, Deliege-Sequaris, op. cit., pág. 542.

Op. cit., pág. 81.

8 En este sentido, VEDDER, op. cit., pág. 7; en sentido contrario, WOHLFARTH e.a., op. cit. pág. 611 . 
tados miembros, reunidos o no en Consejo, es algo que el Tribunal de Justicia ya ha declarado, deduciendo de ello todas las posibles consecuencias prácticas (en particular, negándose a tener en cuenta toda modificación introducida inválidamente) ${ }^{9}$. Como ya vimos antes, en lo relativo específicamente al "compromiso de Luxemburgo" la doctrina es unánime en negarle validez jurídica y eficacia revisora con respecto a los Tratados comunitarios.

En la sentencia Defrenne, el Tribunal de Justicia declaró genéricamente que "sin perjuicio de disposiciones específica, la modificación del Tratado únicamente podrá ser el resultado de una revisión efectuada de conformidad con el artículo $236 "{ }^{10}$. En esta misma línea, el Tribunal de Justicia se consideró competente para controlar la compatibilidad con el Derecho comunitario de varios tipos de acuerdos celebrados entre los Estados miembros y que tenían por objeto modificar, derogar o alterar de algún modo el Derecho comunitario ${ }^{11}$.

En cuanto a los acuerdos celebrados entre Estados miembros y terceros países, en la sentencia que fue conocida con el nombre del acuerdo concreto que dio origen a la misma (acuerdo europeo sobre transporte por carretera-AETC) el Tribunal de Justicia declaró que "cuando hayan sido aprobadas disposiciones comunitarias para la realización de los objetivos del Tratado, los Estados miembros no podrán celebrar, al margen de las

9 Véanse las sentencias de 3 de febrero de 1976, asunto 59/75, Manghera, Rec. 1976, pág. 102, y de 8 de abril de 1976, asunto 43/75, Defrenne, Rec. 1976, pág. 479.

10 Cfr. nota anterior; en el sentido de mantener que la revisión (de cualquier disposición) de los Tratados comunitarios tan sólo resulta posible en los términos del artículo 236, véanse las conclusiones del Abogado General A.D. Lamothe, presentadas el 13 de enero de 1971, asunto 37/70, Rewe, Rec. 1971, pág. 41, así como las del Abogado General J.-P. Warner, presentadas el 8 de octubre de 1980 , asunto 814/79, Rüffner, Rec. 1980, pág. 3832. En este sentido, véase la doctrina: LoUIS, última op. cit., pág. 558; WAELBROECK: Le Droit, cit., pág. 542; BERNHARDT, op. cit., pág. 81.

${ }_{11}$ Cfr. sentencia de 6 de octubre de 1976, asunto 12/76, Tessili, Rec. 1976, pág. 1485, en donde se declaró que los convenios celebrados entre los Estados miembros en virtud del artículo 220 del Tratado CEE deben interpretarse uteniendo en cuenta simultáneamente el sistema y los objetivos que les sean propios y su conexión con el Tratado"; sentencia de 15 de enero de 1986, asunto 44/84, Hurd, Rec. 1986, pág. 81, en donde se declaró que el párrafo segundo del artículo 5 del Tratado CEE puede servir como criterio para determinar la validez de las medidas de ejecución de los Convenios celebrados entre los Estados miembros fuera del ámbito de aplicación de los Tratados, que obstaculicen la aplicación de las disposiciones del Derecho comunitario o el funcionamiento de las Instituciones comunitarias. 
Instituciones comunes, acuerdos que puedan afectar a tales disposiciones o modificar el alcance de las mismas" 12.

En lo relativo a los acuerdos mixtos - celebrados entre los Estados miembros y la Comunidad, por una parte, y terceros países, por otra-, el Tribunal de Justicia todavía no se ha pronunciado claramente. Al parecer, sin embargo, "en ningún caso una infracción del Tratado CEE podrá ser "amparada" por la celebración mixta». Con otras palabras, siendo su objetivo único y exclusivo el de suplir la incompetencia (parcial) de la Comunidad por razón de la materia, la participación de los Estados miembros en el acuerdo mixto no basta para sustraer al control del Tribunal de Justicia la posible incompatibilidad con el Derecho comunitario primario de las disposiciones de dicho acuerdo que estén incluidas en la competencia de la Comunidad ${ }^{13}$.

Parece indiscutible que un Tratado de revisión firmado y ratificado por los Estados miembros al margen del procedimiento que para tal fin prevé el Derecho comunitario, al no ser un acto de una Institución comunitaria en el sentido del artículo 173 del Tratado CEE, no estará sujeto al control de legalidad por parte del Tribunal de Justicia que puede conducir a una declaración de nulidad. Pero parece también seguro que el Tribunal de Justicia podrá anular la decisión de apertura de una conferencia intergubernamental con vistas a la revisión de los Tratados adoptada por el Consejo sin haber recabado antes la opinión del Parlamento y/o de la Comisión, basándose en la existencia de un vicio sustancial de forma ${ }^{14}$. También puede considerarse indiscutible que, a instancia de la Comisión y con arreglo al artículo 169 del Tratado de Roma, el Tribunal de Justicia podrá declarar el incumplimiento por parte de los Estados miembros de las obli-

12 Cfr. sentencia de 31 de marzo de 1971, Comisión c/ Consejo, asunto 22/70, Rec. 1971, pág. 274.

13 Cfr. Louls, última op. cit., pág. 556; en el sentido de mantener la imposibilidad de principio de que el Tribunal de Justicia ejerza cualquier tipo de control sobre un acuerdo mixto, firmado y ratificado por los Estados miembros, R. JOLIET: Le droit institutionnel des Commurautés Européennes. Lieja, 1983, pág. 251; en términos que reflejan ciertas dudas, véanse las conclusiones del Abogado General $M$. Darmon, presentadas el 1 de junio de 1989 en el asunto $C-241 / 87$, Maclaine Watson, Rec. 1990, pág. I- 1815-1816.

14 En la sentencia de 29 de octubre de 1980, asunto 138/79, Roquette Frères, Rec. 1980, pág. 3.360, el Tribunal de Justicia anuló un acto jurídico-comunitario aprobado por el Consejo siguiendo el procedimiento legislativo ordinario (Reglamento $n .{ }^{\circ} 1293 / 79$ ), basándose en el vicio sustancial de forma consistente en no haberse recabado la opinión del Parlamento Europeo. Parecería lógico que, con mayor razón, el Tribunal de Justicia debiera proceder a la anulación cuando se tratara del procedimiento de revisión de los Tratados, que tiene mucha más trascendencia. 
gaciones que les incumben en virtud del artículo 236, así como negarse a aplicar las disposiciones del Tratado de revisión que se haya adoptado al margen del procedimiento de Derecho comunitario que corresponda ${ }^{15}$. Teniendo en cuenta asimismo las facultades de que, según el Tratado de Maastricht, va a disponer el Tribunal de Justicia para hacer que los Estados miembros cumplan sus sentencias, difícilmente podrá afirmarse que las cláusulas de revisión están desprovistas de garantías y dependen de la voluntad de aquéllos.

Como ya vimos antes, tan sólo en dos ocasiones el Tribunal de Justicia pudo haber tenido que intevernir en materia de revisión de los Tratados. En todos los demás casos, el procedimiento de revisión fue observado en su integridad. Esos dos casos, en los que se procedió a la revisión del Tratado CECA contraviniendo las respectivas cláusulas, fueron más tarde objeto de críticas pertinentes que tuvieron cierta repercusión ${ }^{16}, y$ hoy se consideran como errores fruto de la inexperiencia ${ }^{17}$. Los Estados miembros parecen plenamente conscientes de que no pueden prescindir de los procedimientos de revisión de los Tratados europeos. Tan sólo circunstancias excepcionales que impidan la aplicación de las cláusulas de revisión podrán justificar, en su caso, que se recurra al procedimiento ordinario de Derecho internacional ${ }^{18}$.

Como ha podido comprobarse a lo largo de esta exposición, el contenido de las cláusulas de revisión, «llave que abre y cierra todo el sistema de los Tratados", y su garantía no impiden que se responda afirmativamente a la pregunta de si puede hablarse en rigor de un Derecho constitucional europeo autónomo en relación con los Estados miembros. Tampoco lo impide la aplicación práctica de tales cláusulas. Por lo tanto, no es (o ya no es) el modo de revisión lo que caracteriza la diferencia específica entre una Constitución y los Tratados europeos.

15 En este sentido, WeILER y Modrall, op. cit., pág. 166; LouIs: "La révision», cit., pág. 195.

16 La cuestión fue incluso objeto de vivo debate en el Parlamento holandés, impulsado por el diputado Van der Goes van Naters, que le dedicó un estudio que aún hoy conserva su actualidad.: "La revisión de los Tratados supranacionales", en Liber amicorum Jean Pierre François, Leida, 1959, pág. 120 y ss. cit., pág. 195.

17 En este sentido, WeILER y MODRALL, op. cit., pág. 166; LouIs: "La révision",

18 En este sentido, SMit y Herzog, op. cit., pág. 350; Bernhardt, op. cit., pág. 81; en los dos casos de revisión del Tratado CECA al margen del procedimiento previsto para ello, se alega que existieron circunstancias excepcionales que justificaban la invocación de la cláusula rebus sic stantibus. Sin embargo, dicha cláusula no fue invocada expresamente; cfr. VAN NATERS, op. cit., pág. 123. 
Por su parte, no se responde debidamente a la cuestión de determinar si los Estados miembros son todavía dueños de los Tratados con la constatación indiscutible de que las Comunidades (todavía) no son dueñas de ellos. Del mismo modo en que la constatación de que las Comunidades no son un Estado federal no basta para, basándose en criterios de dicotomía, considerarlas una organización internacional como las demás, el hecho de que las Comunidades no dispongan de los Tratados no basta para considerar que los Estados miembros pueden disponer de ellos, pasando por alto los procedimientos previstos para su revisión. En este preciso aspecto, se está cerca de un Estado de Derecho, en el que tal cuestión no se plantea 0 , de plantearse, tan sólo puede obtenerse la respuesta de que nadie es dueño de la única entidad soberana en el mismo, es decir, la Constitución. Tan sólo si se mantiene este estado de cosas podrá continuar hablándose en rigor de una Comunidad de Derecho. 